\title{
The Utility of Plasma Transthyretin and Antioxidants as aBiomarker of Early Pregnancy Loss - A Pilot Study
}

\author{
Sen M. ${ }^{1}$, Goenka L. ${ }^{2}$, Jha D. ${ }^{3}$, Raj V. ${ }^{4}$, Charles S. ${ }^{5}$, Mala K. ${ }^{6}$, George M. ${ }^{7}$ \\ ${ }^{1}$ Dr. Maitrayee Sen, Department of Obstetrics and Gynaecology, ${ }^{2}$ Ms. Luxitaa Goenka, Department of Clinical \\ Pharmacology, ${ }^{3}$ Ms.Durga Jha, Department of Clinical Pharmacology, ${ }^{4}$ Mr.Vijay Raj, Department of Medical Research, \\ ${ }^{5}$ Ms. Soniya Charles, Department of Biotechnology, ${ }^{6}$ Dr. Kanchana Mala, Department of Medical Research, ${ }^{7}$ Dr. Melvin \\ George, Department of Clinical Pharmacology, all authors are affiliated with SRM MCH \& RC, Kattankulathur, \\ Chennai, Tamil Nadu, India.
}

Corresponding Author: Dr. Melvin George, Department of Clinical Pharmacology, SRM MCH \& RC, Kattankulathur, Chennai, Tamil Nadu, India. E-mail:melvingeorge2003@gmail.com

\begin{abstract}
Objective: Miscarriage or early pregnancy loss (EPL) affects about 15-25\% of all pregnancies and is considered as one of the most common complications of the human reproduction. The objective of this pilot study was to quantify and compare the levels of plasma Transthyretin (TTR) and total antioxidant capacity (TAC)among EPL patients and normal pregnant women. Design: Cross sectional pilot study. Subjects: Patients diagnosed with EPL in their first trimester (Incomplete and Missed abortion) and medically terminated pregnancy (MTP) and pregnant women in their first trimester of pregnancy without any complications. Methods: Plasma TTR and total antioxidantcapacity were quantified using Enzyme Linked Immunosorbent Assay (ELISA) and Trolox equivalent antioxidant capacity assay respectively. Statistical analyses were performed with SPSS software version 16.0 (SPSS Inc., Chicago, IL). All p values $<0.05$ were considered statisticallysignificant. Results: A total of 60 subjects were enrolled in the study. There was no significant difference in the mean concentration of plasma TTR among women with EPL 322.20(187.33-444.10) $\mu \mathrm{g} / \mathrm{ml}$ and normal pregnant women 224.32(176.06-509.97) $\mu \mathrm{g} / \mathrm{ml}(\mathrm{p}=0.501)$. However, a significant difference was observed in the TACamong women with EPL $0.58(0.51-0.70) \mathrm{mM} / \mu 1$ and normal pregnant women $0.71(0.63-0.79) \mathrm{mM} / \mu \mathrm{l}(\mathrm{p}=0.006)$. No significant correlation was seen between TTR and antioxidant capacity. Conclusion: Our study failed to demonstrate any relationship between plasma TTR levels and EPL. Antioxidant capacity was lower among EPL patients suggesting the importance of supplementation with antioxidants to prevent poor outcomes in pregnancy.
\end{abstract}

Keywords: Early pregnancy loss, Transthyretin, Antioxidants

\section{Introduction}

Miscarriage or early pregnancy loss (EPL) affects about $15-25 \%$ of all pregnancies, and is considered as one of the most common complication of the human reproduction. The most common etiologies of EPL include the genetic or chromosomal abnormalities in the developing embryo, endocrine diseases, immunological factors, chemical agents, hereditary disorders, and psychological factors.Oxidative stress which is defined as an imbalance between pro-oxidants and antioxidant capacityhas been implicated in many reproductive and pregnancy disorders such as sub fertility to miscarriage, maternal vascular disease and preterm labour [1].

Manuscript received: $6^{\text {th }}$ February 2019

Reviewed: $17^{\text {th }}$ February 2019

Author Corrected: $23^{\text {th }}$ February 2019

Accepted for Publication: $1^{\text {st }}$ March 2019
Burton and Jauniax et al. suggested that there was an increase in the oxidative stress markers in placenta tissue among EPL patients when compared to controls. This indicated an increase in the reactive oxygen species (ROS) which was due to premature establishment of maternal perfusion. Thus, the increase in oxidative stress may be associated with EPL [2].

Transthyretin (TTR), a 56-kDa homotetrameric protein, belongs to a group of proteins including thyroxinebinding globulin and albumin which is mainly synthesized in the liver, eye and choroid plexus. TTR is down regulated in the placental villous trophoblasts of early pregnancy loss in human. TTR plays a critical role in the transportation of the thyroid hormone, thyroxin (T4) in the blood and retinol through an association 


\section{Original Research Article}

with retinol binding protein (RBP); which are both critical for the neurological development of the fetus [3]. The secretion of TTR from the placenta is known to play a vital role in the transportation of the maternal thyroid hormone to the fetal circulation through the formation of the TTR-T4 complex. The formation of this complex protein TTR-T4 is considered important for the normal development of the fetus $[4,5]$.

It has been observed that the fetus begins to secrete thyroid hormone only after 12 weeks of gestation and until this time the fetal thyroid hormone supply originates from the mother and this is thought to continue throughout the pregnancy period.

The perseverance of high levels of deiodinase type 3 activity in the placenta is thought to inactivate $T_{4}$ to its inactive form $\mathrm{rT}_{3}$. The existence of placental TTR in the $6^{\text {th }}$ week of gestation will aid in the binding maternal $T_{4}$, which in turn will prevent deiodination and its delivery to fetal capillaries [6].

Down regulation of TTR during the first trimester pregnancy may lead to fetal growth restriction and development of pre-eclampsia [7-9]. Therefore, we hypothesized that the plasma levels of TTR might be low in EPL, suggesting thatTTR might be used as asuitable diagnostic marker for EPL and a potential therapeutic target in preventing subsequent miscarriage.

The deficiencies in the antioxidant activities might result in poor pregnancy outcomes such as fetal growth restriction and preeclampsia [10]. Therefore, the measurement of plasma antioxidants can be a suitable diagnostic novel marker for EPL. Hence, we also attempted to measure the antioxidant concentration among study subjects. Therefore, the objective of our study was to quantify the levels of plasma TTR andtotalantioxidant capacity among patients with EPL and patients with normal pregnancy.

\section{Methods}

Study Population, type of study and ethical consideration:This was a cross-sectional pilot study performed in the Department of Obstetrics and Gynaecology and Clinical Pharmacology of a tertiary care hospital between January and August 2017. The study was approved by the institutional ethics committee. Thy study was Compliant with the Ethical Requirements. The study involved human participants.

The Informed Consent Informed consent was obtained from all individual participants included in this study.
Inclusion and exclusion criteria: Patients were diagnosed with EPL in their first trimester (Incomplete and Missed abortion) were considered eligible for inclusion into the study as cases. Patients who visited the outpatient department for medically terminated pregnancy (MTP) and pregnant women in their first trimester of pregnancy without any complications were considered eligible for inclusion as normal controls (NCs). We excluded patients with baseline hypertension, proteinuria, renal disease, diabetes, and twin pregnancy. Other exclusion criteria included patients with any major or minor fetal anomaly and chromosomal abnormalities.

Clinical collection of data: Clinical and demographic data were collected on patient age, waist and hip circumference, body mass index (BMI), gestational weeks and last menstrual period (LMP). Data were also collected on other risk factors such as consumption of coffee and use of oral contraceptives (OCPs).Blood sampling was done to determine the level of hemoglobin $(\mathrm{Hb})$, serum creatinine $(\mathrm{SCr})$, blood urea and platelet count.

\section{Laboratory Investigations}

Enzyme Linked Immunosorbent Assay (ELISA): After obtaining the written informed consent from all patients, $4 \mathrm{ml}$ of blood sample was collected from the ante-cubital vein in the forearm. After adequate centrifugation at 2500 revolutions per minute (rpm) for 10 minutes, the plasma samples were extracted and were stored in $-80^{\circ} \mathrm{C}$ deep freezer. The plasma which was centrifuged from the blood sample was subjected to competitive enzyme-linked immunosorbent assay (ELISA) for the measurement of protein TTR.

The assay was performed according to the manufacturer's instructions provided inthe commercially available Human Transthyretin ELISA Kit (Bioassay Technology Laboratory, Cat. No E0000Hu, Shanghai, China). Inter and intra-assay coefficient of variation (CV's) was $6 \%$ and $8 \%$, respectively. The measurement of TTR was done in a blinded fashion as the investigators who performed the ELISA assay were not informed about the patient's diagnosis.

Antioxidant assay: Plasma antioxidant capacity was measured by TEAC (Trolox equivalent antioxidant capacity) assay. It was performed according to the manufacturer's recommendations as provided in the commercially available kit (Antioxidant Assay kit, Sigma-Aldrich, Missouri, USA). 


\section{Original Research Article}

The assay is based on scavenging of ABTS+ which is produced from oxidization of ABTS [2,2'-Azino-bis(3ethylbenzthiazoline-6-sulfonic acid)]. Antioxidants available in the plasma sample derived from patient's blood sample neutralize the radical cation, ABTS + in a concentration dependent manner. Since ABTS + is a chromogenic compound, the colour intensity was determined by spectrophotometer at $405 \mathrm{~nm}$ (Infinite F50 ELISA Plate Reader, Tecan Group Ltd, Mannedorf, Switzerland). It utilizes Trolox, a synthetic watersoluble antioxidant analogous to Vitamin E, which is used to express standard and samples as Trolox equivalent $(\mathrm{mM})$ based on a Trolox standard curve. Inter and intra-assay CV's were $7 \%$ and $8 \%$, respectively. The lab measurements were done in a blinded fashion as the investigators who performed the assay were unaware about the patient's diagnosis.
Statistical Analysis: The normality of data for continuous variables was checked using Q-Q plot in SPSS. Continuous variables were summarized as mean \pm standard deviation (SD) or median (IQR) and categorical data were expressed as frequency and percentages. Differences in the categorical variables between groups were evaluated using the chi-square test. Parametric or non-parametric tests wereused based on the distribution of data. The differences in continuous variables between groups were analyzed with Mann-Whitney $U$ test or Independent Sample $t$ Test based on normality of data. Spearman and Pearson correlation was done to establish the relation between the laboratory assays. All statistical analyses were performed with SPSS software version 16.0 (SPSS Inc., Chicago, IL). All $\mathrm{p}$ values $<0.05$ were considered statisticallysignificant.

\section{Results}

A total of 60 subjects were enrolled in the study. The study participants comprised of two groups: patients withmissed/incomplete abortion $(\mathrm{n}=30)$ and controls comprised ofpatients with uncomplicated pregnancy $(n=30)$.Allinformation on the baseline demographic data, clinical variables, laboratory investigations and risk factors were collected (Table1). There were no significant differences in the baseline demographic and clinical variables between the two groups. Significant differences were not observed in the laboratory investigations, platelet count, blood urea and serum creatinine between thetwo groups.

Table-1: Baseline Characteristics Including Demographics, Risk Factors and Laboratory findings of Study Patients

\begin{tabular}{|l|c|c|c|}
\hline Patient Characteristics & $\begin{array}{c}\text { Missed Abortion/Incomplete } \\
\text { Abortion } \\
\text { (n=30) }\end{array}$ & $\begin{array}{c}\text { Uncomplicated/Normal } \\
\text { Pregnancy } \\
\text { (n=30) }\end{array}$ & p-value \\
\hline Age, years & $25.33 \pm 3.94$ & $24.93 \pm 3.80$ & 0.285 \\
\hline BMI, kg/m s $^{2}$ & $22.91 \pm 4.73$ & $24.85 \pm 3.68$ & 0.186 \\
\hline Systolic Blood Pressure, mm Hg & $111.72 \pm 5.31$ & $110.41 \pm 9.40$ & 0.808 \\
\hline Diastolic Blood Pressure, mm Hg & $72.33 \pm 8.98$ & $73.05 \pm 8.30$ & 0.783 \\
\hline Heart Rate, PR & $81.63 \pm 5.01$ & $79.55 \pm 6.73$ & 0.214 \\
\hline No. of gestational weeks & $9.56 \pm 3.02$ & $8.96 \pm 3.49$ & 0.508 \\
\hline Platelet count, per cu mm & $282840 \pm 53434.6$ & $228760 \pm 97411.2$ & 0.067 \\
\hline Blood urea, mg/dL & $15.28 \pm 5.76$ & $15.50 \pm 3.16$ & 0.919 \\
\hline Serum creatinine, mg/dL & $0.49 \pm 0.12$ & $0.5 \pm 0.05$ & 0.780 \\
\hline Coffee Intake (Yes/No) & $2(6.7 \%)$ & $7(23.3 \%)$ & 0.070 \\
\hline $\begin{array}{l}\text { Use of Oral Contraceptives } \\
\text { (Yes/No) }\end{array}$ & $2(6.7 \%)$ & $3(10 \%)$ & 0.316 \\
\hline
\end{tabular}

There was no significant difference in the median concentration of plasma TTR among patients with missed/incomplete abortion and controls [322.20 (187.33-444.10) $\mu \mathrm{g} / \mathrm{mlversus} 224.32(176.06-509.97) \mu \mathrm{g} / \mathrm{ml}$ ( $\mathrm{p}=0.501)]$ respectively (Figure 1a). However, a significant difference was observed in themedian total antioxidant capacityamong patients with $\mathrm{missed} /$ incomplete abortion and controls $[0.58(0.51-0.70) \mathrm{mM} / \mu 1$ versus $0.71(0.63-0.79) \mathrm{mM} / \mu 1(\mathrm{p}=0.006)]$ respectively (Figure 1b). No significant correlation was observed between plasma TTR and antioxidant capacity. Furthermore, no significant correlation was observed between gestational weeks, and antioxidant capacity and gestational weeks respectively. 


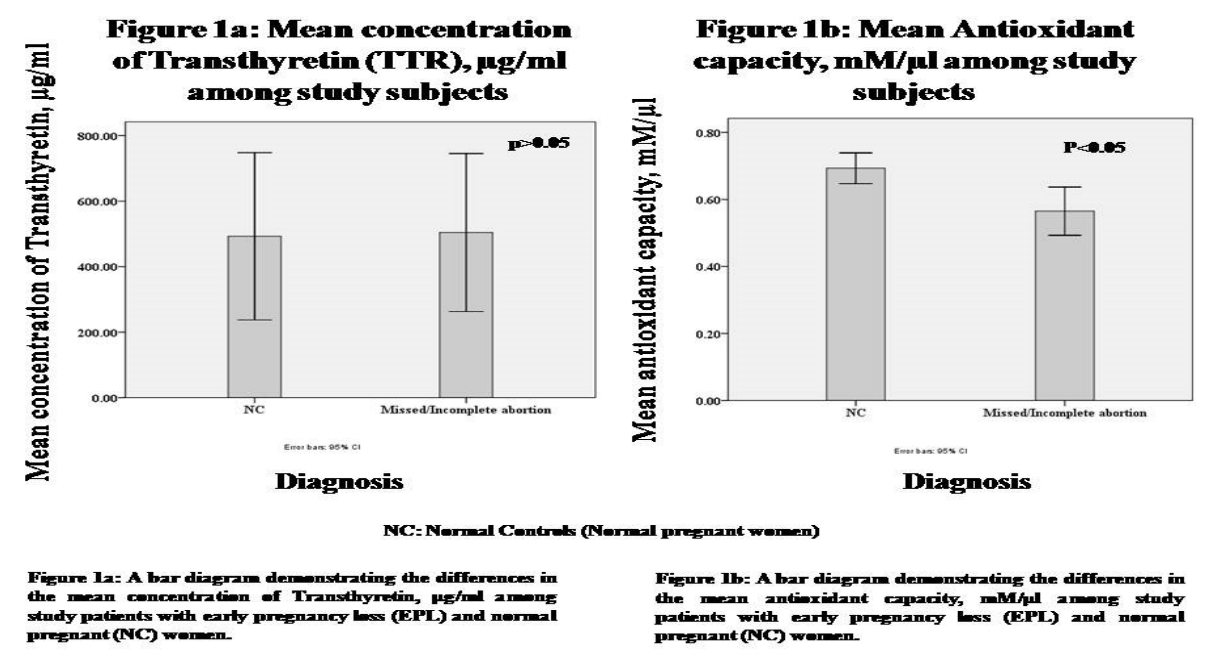

\section{Discussion}

To the best of our knowledge this is the first clinical study that studied and compared the plasma levels of TTR among women with EPL and uncomplicated pregnancy. The present study compared the levels of TTR among women with EPL and uncomplicated pregnancy.

There are only few clinical studies that measured the plasma levels of TTR among pregnant women in their first trimester. However, most of these studies were performed among pregnant women with preeclampsia [9, 11-12]. The TTR levels observed in our study $(224.32 \mu \mathrm{g} / \mathrm{ml})$ were in consensus with the study performed by Fruscalzo et al $(211 \mu \mathrm{g} / \mathrm{ml})$ [9].

The present study failed to demonstrate any significant difference in the plasma levels of TTR among women with EPL and women without any complications in their pregnancies. Ourstudy results did not match the results of the study which was performed by Liu et al. and colleagues,where proteomic analysis on the alteration of protein expression in the placental villous tissue of EPL was done. The study revealed that there were reasonable decreases in the grade of TTR protein staining in the cytoplasm of syncytiotrophoblastic and/or cytotrophoblastic cells in placental villous tissues obtained from the EPL group compared to women with uncomplicated pregnancy [13].

Although in a study performed by Episkopou et al. TTR deficient mice reported normal fertility, some of the recent studies reported that the protein might play an important role in the early stages of pregnancy [14]. The down regulation of TTR, a protein involved in the vitamin A and thyroid hormone metabolism may play a vital role in the pathological development of EPL.
However, studies have reported that the progesterone receptor plays a role in the up regulation and synthesis of TTR, secretion and uptake of TTR by human placenta have also been reported. Recent studies have reported the internalization of TTR by trophoblast and in the presence of T4, there is an increase in the uptake of TTR [4, 15-16]. Therefore, in consensus with our study it may be hypothesized that an increase in the plasma levels of TTR among women with EPL than in women with uncomplicated pregnancy can be explained by the theory of decreased internalization of TTR by trophoblasts.

In EPL there is deficiency of progesterone as well as deficiency of $\mathrm{T} 4$ in the maternal circulation which may prevent the internalization of TTR and thus increase the serum level of TTR and simultaneously decrease the local TTR at placental villous tissue $[17,18]$.

Furthermore, clinical studies measuring TTR levels were performed among pregnant women with preeclampsia.The studies showed that TTR levels were lower among women with severe preeclampsia in each month of gestation than among women with normal pregnancy [9, 11-12]. Therefore, the production of TTR by trophoblasts demonstrateda mechanism that helps in the transfer of maternal thyroid hormone to the fetal circulation which could have clinical implications in the fetal development [6]. Our study showed that the totalantioxidant capacity was significantly higher among women with uncomplicated pregnancy when compared to women with EPL. Similar results were seen in other studies where the antioxidant capacity was lower among women who had a first trimester miscarriage than that of healthy women in their first trimester pregnancy [19]. 


\section{Original Research Article}

The total antioxidant status (TAS) and copper $(\mathrm{Cu})$ was significantly lower among women who experienced EPL than that of the normal pregnant women. In another study performed by Jenkins et al., it was observed that women suffering from EPL had significantly lower levels of antioxidants superoxide dismutase (SOD) when compared to women whose pregnancies were successful [20]. During the first trimester pregnancy, the abnormal placentation would cause oxidative stress that result in the endothelial dysfunction. This would lead to the emergence of pregnancy complications such as abortion [21]. The excess production of reactive oxygen species (ROS) will lead to the cellular damage of DNA, lipids and cellular proteins.

The supplementation of antioxidants can protect the cells from peroxidation reactions that can prevent cellular damage and can also help in the maintenance of cellular integrity [22].

Furthermore, studies have also shown that oxidative stress is associated with recurrent pregnancy losses [2325]. Therefore, measuring the antioxidant levels might be considered as a novel diagnostic marker for EPL and supplementation with adequate antioxidants might provide a substantial therapeutic benefit. We also attempted to study the relationship between TTR and gestational weeks among the study patients.

However, our study failed to produce any correlation between gestational age and TTR. In a study, the changes in placental TTR in early and late pregnancy was measured where placentas were collected from the surgically terminated pregnancies between 6 and 17 weeks of gestation and compared with the normal term between 38 to 39 weeks following the caesarean section. The laboratory methods used for deterring the TTR mRNA and protein levels were Real timePolymerase Chain Reaction, western blotting and immunohistochemistry. The study demonstrated a significant increase in the expression of TTR mRNA and TTR proteins between $6^{\text {th }}$ and $13^{\text {th }}$ weeks of gestation; however, this increase in expression was not seen between $13^{\text {th }}$ and $17^{\text {th }}$ weeks [26]. Our study being limited to women in their first trimester of pregnancy $(<12$ weeks) may be one of the reasons for the failure to produce any significant correlation between TTR and gestational weeks. During the first trimester of pregnancy the placenta remains relatively hypoxic and there will be an increase in the oxygen level to an average of about $2.5 \%$ at 8 weeks and $8.5 \%$ at 12 weeks which remains stable until delivery $[27,28]$.
The increase in the levels of oxygen leads to the production of TTR in JEG-3 human choriocarcinoma cells. Therefore, it has been hypothesized that the production of TTR is increased during the first trimester pregnancy and the expression remains constant throughout the gestation [29]. Our study is a preliminary, pilot study with a small sample size and the samples being collected at different points of time during first trimester. Due to logistic reasons, we did not measure the mRNA expression of TTR among the study patients from the products of conception, an indirect method of estimation of TTR locally at placental tissue.

Our study failed to demonstrate any relationship between plasma TTR levels and early pregnancy loss. Antioxidant capacity was lower among EPL patients suggesting the importance of supplementation with antioxidants to prevent poor outcomes in pregnancy. Future studies should be directed towards understanding the role of transthyretin in early pregnancy loss using a larger cohort of subjects.

Source of funding \&Acknowledgments: The project was funded by SRM Institute of Science and Technology (SRMIST) under Grant [SRMIST-SEI2016-04-095]. We would also like to thank Ms. Masum Sharma and Ms. Kamatchi M for their contribution to the study.

Conflict of interest:The authors declare that they do not have any conflict of interest. All authors have read and approved the manuscript.

\section{Author contributions}

1. Maitrayee Senwas involved in the conception and design of the work, analysis and interpretation of data for the work, drafting of the manuscript and approving the final version to be published.

2. Luxitaa Goenka was involved in the acquisition of data for the work, analysis and interpretation of data for the work, drafting of the manuscript and approving the final version to be published.

3. Durga Jha was involved in the acquisition of data for the work, analysis and interpretation of data for the work, and approving the final version to be published. 4. Vijay Raj was involved in the acquisition of data for the lab work, analysis and interpretation of data for the work, and approving the final version to be published. 5. Soniya Charles was involved in the acquisition of data for the lab work analysis and interpretation of data for the work, and approving the final version to be published. 


\section{Original Research Article}

6. Kanchana Mala was involved in the acquisition of data for the lab work analysis and interpretation of data for the work, and approving the final version to be published.

7. Melvin George was involved in the conception and design of the work, analysis and interpretation of data for the work, drafting of the manuscript and approving the final version to be published. Melvin George is also accountable for all aspects of the work in ensuring that questions related to the accuracy or integrity of any part of the work are appropriately investigated and resolved.

\section{Impact Statement}

What is already known on this subject?Transthyretin has been associated with the neurological development of fetus and it is down regulated in the placental villous trophoblasts of early pregnancy loss in human. Oxidative stress has been associated with many reproductive complications such as infertility, miscarriage, pre-eclampsia, fatal growth restriction and preterm labour.

What the results of this study add?- The present study is in consensus with the existing literature that measurement of total antioxidant capacity could be a suitable diagnostic marker for EPL; however, the present study failed to demonstrate relationship between plasma Transthyretin and early pregnancy loss.

\section{What the implications are of these findings for clinical practice and/or further research?}

The supplementation of antioxidants can prevent poor pregnancy outcomes. Future studies should be directed towards understanding the role of transthyretin in early pregnancy loss using a larger cohort of subjects.

\section{Funding: Nil, Conflict of interest: Nil \\ Permission from IRB: Yes}

\section{References}

1. Duhig K, Chappell LC, Shennan AH. Oxidative stress in pregnancy and reproduction. Obstet Med. 2016 Sep;9(3):113-6. doi: 10.1177/1753495X16648495 Epub 2016 May 17.

2. Jauniaux E, Burton GJ. Pathophysiology of histological changes in early pregnancy loss. Placenta. 2005 Feb-Mar;26(2-3):114-23.

3. Haddow JE, Palomaki GE, Allan WC, et al. Maternal thyroid deficiency during pregnancy and subsequent neuropsychological development of the child. N Engl J Med. 1999 Aug 19;341(8):549-55.
4. Landers KA, McKinnon BD, Li Het al. Carriermediated thyroid hormone transport into placenta by placental transthyretin. J Clin Endocrinol Metab. 2009 Jul;94 (7):2610-6. doi: 10.1210/jc.2009-0048. Epub 2009 Apr 28.

5. Fleming CE, Nunes AF, Sousa MM. Transthyretin: more than meets the eye. Prog Neurobiol. 2009 Nov;89(3):266-76. doi: 10.1016/j.pneurobio. 2009.07. 007. Epub 2009 Aug 7.

6. Landers KA, Mortimer RH, Richard K. Transthyretin and the human placenta. Placenta. 2013 Jul;34(7):513-7. doi: 10.1016/j.placenta.2013.04.013. Epub 2013 May 9.

7. Fruscalzo A, Schmitz R, Klockenbusch W, Köhler G, Londero AP, Siwetz M, et al. Human placental transthyretin in fetal growth restriction in combination with preeclampsia and the HELLP syndrome. Histochem Cell Biol. 2012 Dec;138 (6):925-32.doi: 10.1007/s00418-012-0997-1. Epub 2012 Jul 31.

8. Wang Q, Liu C, Zhang Z. Transthyretin and Normal Human Pregnancy: Mini Review. Crit Rev Eukaryot Gene Expr. 2016;26(3):273-7. doi: 10.1615/CritRev EukaryotGeneExpr.2016017323.

9. Fruscalzo A, Biasioli A, Londero AP, Ceraudo M, Stel G, Bertozzi S, et al. Retinol binding protein as early marker of fetal growth restriction in first trimester maternal serum. Gynecol Endocrinol Off J Int Soc Gynecol Endocrinol. 2013 Apr;29(4):323-6.doi: 10.3109/09513590.2012.743013. Epub 2013 Jan 25.

10. Mistry HD, Gill CA, Kurlak LO, et al. Association between maternal micronutrient status, oxidative stress, and common genetic variants in antioxidant enzymes at 15 weeks' gestation in nulliparous women who subsequently develop preeclampsia. Free Radic Biol Med. 2015 Jan;78:147-55. doi: 10.1016/j. freeradbiomed.2014.10.580. Epub 2014 Nov 6.

11. Zhu L, Chen Y, Liu C, et al. Transthyretin as a novel candidate biomarker for preeclampsia. Exp Ther Med. 2014 May;7(5):1332-1336. Epub 2014 Feb 18.

12. Vascotto C, Salzano AM, D'Ambrosio C, et al. Oxidized transthyretin in amniotic fluid as an early marker of preeclampsia. J Proteome Res. 2007 Jan;6 (1):160-70.

13. Liu AX, Jin F, Zhang WW, et al. Proteomic analysis on the alteration of protein expression in the placental 


\section{Original Research Article}

villous tissue of early pregnancy loss. Biol Reprod. 2006 Sep;75(3):414-20. Epub 2006 May 31.

14. Episkopou V, Maeda S, Nishiguchi S, et al. Disruption of the transthyretin gene results in mice with depressed levels of plasma retinol and thyroid hormone. Proc Natl Acad Sci U S A. 1993 Mar 15;90(6):2375-9.

15. Divino CM, Schussler GC. Receptor-mediated uptake and internalization of transthyretin. J Biol Chem. 1990 Jan 25;265(3):1425-9.

16. Sousa MM, Saraiva MJ. Internalization of transthyretin. Evidence of a novel yet unidentified receptor-associated protein (RAP)-sensitive receptor. J Biol Chem. 2001 Apr 27;276(17):14420-5. Epub 2001 Jan 24.

17. Hussain M, El-Hakim S, Cahill DJ. Progesterone supplementation in women with otherwise unexplained recurrent miscarriages. J Hum Reprod Sci. 2012 Sep;5(3):248-51. doi: 10.4103/0974-1208.106335.

18. Lepoutre T, Debiève F, Gruson D, et al. Reduction of miscarriages through universal screening and treatment of thyroid autoimmune diseases. Gynecol Obstet Invest. 2012;74 (4):265-73. doi: 10.1159 /000343759. Epub 2012 Nov 10.

19. Omeljaniuk WJ, Socha K, Borawska MH, et al. Antioxidant status in women who have had a miscarriage. Adv Med Sci. 2015 Sep;60(2):329-34. doi: 10.1016/j.advms.2015.06.003. Epub 2015 Jul 5.

20. Jenkins C, Wilson R, Roberts J, et al. Antioxidants: their role in pregnancy and miscarriage. Antioxid Redox Signal. 2000 Fall; 2(3):623-8. DOI:10.1089/ 15230860050192369

21. Poston L, Raijmakers MT. Trophoblast oxidative stress, antioxidants and pregnancy outcome--a review. Placenta. 2004 Apr; 25 Suppl A:S72-8.
22. Poston L, Igosheva N, Mistry HD, et al. Role of oxidative stress and antioxidant supplementation in pregnancy disorders. Am J Clin Nutr. 2011 Dec;94(6 Suppl):1980S-1985S. doi: 10.3945/ajen.110.001156. Epub 2011 May 25.

23. Baban RS. Oxidative stress in recurrent pregnancy loss women. Saudi Med J. 2010 Jul;31(7):759-63.

24. Yiyenoğlu ÖB, Uğur MG, Özcan HÇ, et al. Assessment of oxidative stress markers in recurrent pregnancy loss: a prospective study. Arch Gynecol Obstet. 2014 Jun;289(6):1337-40. doi: 10.1007/s00404013-3113-4. Epub 2013 Dec 3.

25. Simşek M, Naziroğlu M, Simşek H, et al. Blood plasma levels of lipoperoxides, glutathione peroxidase, beta carotene, vitamin $\mathrm{A}$ and $\mathrm{E}$ in women with habitual abortion. Cell BiochemFunct. 1998 Dec;16(4):227-31.

26. Patel J, Landers KA, Li H, et al. Ontogenic changes in placental transthyretin. Placenta. 2011 Nov;32 (11): 817-22. doi: 10.1016/j.placenta.2011.09.007.Epub 2011 Sep 25 .

27. Schneider H. Oxygenation of the placental-fetal unit in humans. Respir PhysiolNeurobiol. 2011 Aug 31;178(1):51-8. doi: 10.1016/j.resp.2011.05.009. Epub 2011 May 17.

28. Patel J, Landers K, Mortimer RH, et al. Regulation of hypoxia inducible factors (HIF) in hypoxia and normoxia during placental development. Placenta. 2010 Nov;31(11):951-7. doi: 10.1016/j.placenta.2010.08.008. Epub 2010 Sep 24.

29. Patel J, Landers $\mathrm{K}, \mathrm{Li} \mathrm{H}$, et al. Oxygen concentration regulates expression and uptake of transthyretin, a thyroxine binding protein, in JEG-3 choriocarcinoma cells. Placenta. 2011 Feb;32(2):12833.doi: 10.1016/j.placenta.2010.11.016. Epub 2010 Dec 10.

\section{How to cite this article?}

Sen M., Goenka L., Jha D., Raj V., Charles S., Mala K., George M. The Utility of Plasma Transthyretin and Antioxidants as aBiomarker of Early Pregnancy Loss- A Pilot Study. Obs Rev: J obstet Gynecol 2019;5 (1): 6470.doi:10.17511/joog.2019.101.12. 